\title{
An Emerging Engineering Education-Oriented University-Industry Cooperative Practical Teaching Model for Electrical and Information Engineers
}

\author{
He Wen, Zhaosheng Teng, Jing Zhang, Feng Wang, and Zhikang Shuai
}

\begin{abstract}
The subjects of electrical and information bear an important task of transporting high level engineers to the electrical measurement and instrumentation industry. It is of great significance to build a practical project that reflects the latest development of the electrical measurement and instrumentation industry and technology. It is also an important part of the new engineering construction and helps to improve the theoretical level and practical ability of the electrical and information engineers. Combined with the training needs of electrical information professionals in China's electrical measurement and instrumentation industry, this paper explores the design and management ideas of joint electricity measurement practice projects for school-enterprise-oriented engineers trained by electrical and information engineers, and provides reference for relevant teaching reform.
\end{abstract}

Index Terms-Emerging engineering education, subjects of electrical and information, engineer, practice projects, personnel training.

\section{INTRODUCTION}

Emerging engineering education (3E) requires institutions of higher education to expand the education reform of engineering professionals, take advantage of the close relationships between institutions and industries, become oriented to the current and future needs of industrial development, and expand the content and key development areas of engineering programs to vigorously train professionals who are involved in engineering technological and industrial innovations [1]-[3]. Today, 3E-oriented practical teaching has become a focal area in the education reform of electrical and information engineering (EIE) disciplines.

Internships for engineering students have always been a headache for the engineering education community [4], [5]. Businesses feel that students in school are unable to do their jobs, which will not only delay time, but also consume raw materials. The cost of training is high, and the average enterprise cannot afford it. The students believe that the frontline production is complex and it is difficult to complete the actual operation safely and in a standardized manner [6]-[8]. In this way, the very important production internships for engineering students basically become 'walking through' to visit the production line [9], [10].

Manuscript received February 23, 2018; revised March 29, 2018.

H. Wen, Z. Teng, J. Zhang, F. Wang, and Z. Shuai are with the College of Electrical and information engineering, Hunan University, Changsha, 410082, China (e-mail: he_wen82@126.com).
Hunan University offers four EIE majors, namely, electrical engineering and automation, electronic information engineering, automation, and electrical and information technology and equipment, with the aim of training advanced engineering and technological professionals in the equipment design and manufacture, technological development, application research and operations management areas of the EIE field. Therefore, addressing the problems of inadequate practical training and the disconnection between education and industry has become the key to ensuring that $3 \mathrm{E}$ training model reform satisfies relevant industrial development requirements.

In this paper, based on the characteristics of scientific research and teaching at the College of EIE of Hunan University, the demand of the electrical measurement and instrumentation (EMI) industry for system analysis, design, operation and research and development professionals in the forefront of production is analyzed, a 3E-oriented university-industry cooperative practical teaching model for EIE professionals is explored, and university-industry cooperative practicum projects for undergraduate students are designed with the aim of providing a reference for reforming the training plans of relevant specialties.

\section{DEMAND FOR EMI INDUSTRY PROFESSIONALS IN THE 3E BACKGROUND}

\section{A. $3 E$ and EMI Industry}

China's emerging engineering education (3E) construction and action guidelines ("Tianda Action") clearly state the need to update and reform traditional disciplines and specialties, serve the transformation and upgrade of traditional industries, develop toward the middle and high ends of the value chain, provide an impetus to combine existing engineering disciplines and the integration of engineering disciplines and other disciplines, extend applied science disciplines to engineering disciplines, and cultivate and form new interdisciplinary specialties.

Electrical measurement and instrumentation (EMI) is an engineering and technological field that studies and implements various types of static and dynamic, direct or indirect electromagnetic parameters to measure and control instruments or systems. The EMI industry is a typical industry with an integration of electrical, automation, instrumentation and electronic disciplines. After more than 50 years of development, industrial clusters that encompass a complete range of disciplines with a relatively high scientific research capacity have formed in the EMI industry in China, 
which primarily includes fields that develop and manufacture electrical safety inspection and analysis devices for power distribution systems, power supply units, electrical energy meters (EEMs), electromagnetic parameter measurement instruments, electromagnetic parameter analysis and recording devices, standard and calibration devices, automatic meter reading systems (meterless), electrical load management systems, measuring range extending devices, electric power automation instruments and systems, non-electricity electrical measuring instruments and devices and other electrical instruments and products. Currently, the EMI industry in China has more than 700 enterprises that are larger than the designated size, with a production and sale capacity that exceeds 200 million pieces of equipment and a total industrial output value of more than 30 billion yuan. The EMI industry in China is ranked first in the world in terms of production and sales capacity for EEMs and portable digital multimeters. In addition, the EMI industry in China has proprietary intellectual property rights for the majority of products and has one of the highest domestic production rates in China. Currently, the EMI industry in China has an export rate greater than $15 \%$ and very high international competitiveness.

Introducing the latest industrial and technological developments and professional training requirements of the EMI industry in the courses for electrical and information engineering (EIE) undergraduate students of Hunan University and establishing new practicum project resources to help students "get through the last mile of education" are important measures for the conscientious implementation of 3 E reformation.

\section{B. Requirements of the EMI Industry for EIE Professionals}

The training of professionals has vital importance in the development of an industry, such as the EMI industry. The development of the EMI industry requires the continuous integration of new professionals with a continuous drive for innovative development. In less than ten years, the scale of training of professionals in the EMI industry has nearly quadrupled, and both student recruitment and graduate employment have been successful. However, the number of trained professionals remains significantly less than the workforce that is required for the development of the EMI industry.

With development toward virtual, networked and intelligent electrical measurement instruments and systems, interdisciplinarity will become more common, which establishes new requirements for the current training model for EIE professionals in the EMI industry in China.

1) EMI industry-oriented engineering competence: Students should be trained to become familiar with the policies and regulations related to the EMI industry, develop excellent professional ethics and psychological qualities, understand relevant enterprises in the EMI industry in terms of culture, business processes, function division and employee professionalism and nurture the spirit to assiduously learn and passionately work.

2) EMI industry-oriented practical engineering ability: Students should be trained to become familiar with the technical standards related to the EMI industry, systematically master basic theoretical knowledge, basic specialty knowledge and specialty knowledge of the EIE field and develop the ability to develop, design and manufacture instruments and systems and perform technological transformation.

3) EMI industry-oriented engineering innovation ability. Students should be trained to understand the development trend toward virtual, networked and intelligent instruments and systems, become familiar with new materials, technologies and equipment, as well as advanced manufacturing systems, disciplinary frontiers and development trends in the EMI industry, develop an innovative mindset and the initial ability to innovatively apply emergent technologies or technologies from other industries to address practical engineering problems and master their language and written communication capabilities.

\section{DESIGN OF 3E-ORIENTED UNIVERSITY-INDUSTRY COOPERATIVE PRACTICUM PROJECTS}

\section{A. EIE Practicum Projects Oriented to the EMI Industry}

Based on an in-depth integration of Hunan University and the EMI industry, the practical training of EIE students of Hunan University will consist of two stages, namely, the on-campus stage and the enterprise stage. By utilizing complementary advantageous resources of the university and the industry, innovative practicum bases will be established both on campus and off campus. Hunan University-industry cooperative practicum projects for EIE engineers are designed as follows:

1) A systematic method will be employed to conduct all electrical measuring practicum projects in specific electrical measuring systems.

2) The content of the practicum projects is arranged to ensure gradual progression from the elementary to the profound, from the classical to the modern, and from simulation to practicum.

3) The concept of combination of theory and practicum entails practicum teaching, which reflects the content of science-dominated engineering.

4) All practicum projects have an actual engineering background and reflect the principle of industrialization.

5) All practicum projects are typical and representative and can help students understand all aspects of the EMI industry utilizing experience gained at key points.

EIE students of Hunan University are encouraged to participate in university-industry cooperative projects, conduct scientific research and engage in practical training in collaboration with teachers and the industry. During the process of receiving enterprise training and completing their graduation projects, EIE students of Hunan University are guided to abstract practicum teaching and innovative training projects from modern industrial scientific research and the forefront of production; a system for establishing practicum and innovation projects for students will be implemented; and students are encouraged to engage in engineering practicums and innovation via policy and funding support. 
Students will also be encouraged to apply for national, provincial and municipal innovation and entrepreneurship programs. Students will improve their practical ability and creative thinking ability by participation in multilevel, comprehensive practicum and innovation training. Table I summarizes the EIE practicum projects implemented at Hunan University that are oriented to the EMI industry.

TABLE I: PRACTICUM PROJECTS FOR EIE STUDENTS BASED ON THE EMI INDUSTRY

\begin{tabular}{|c|c|c|}
\hline Number & Project Name & Type \\
\hline 1 & $\begin{array}{l}\text { The basics for electrical parameter } \\
\text { measurement }\end{array}$ & $\begin{array}{c}\text { Demonstration and } \\
\text { verification }\end{array}$ \\
\hline 2 & $\begin{array}{l}\text { Standard sources and measuring } \\
\text { transformers }\end{array}$ & $\begin{array}{c}\text { Demonstration and } \\
\text { verification }\end{array}$ \\
\hline 3 & $\begin{array}{l}\text { Experiments on the effects of the } \\
\text { electromagnetic environment on modern } \\
\text { electrical measuring instruments }\end{array}$ & $\begin{array}{c}\text { Demonstration and } \\
\text { verification }\end{array}$ \\
\hline 4 & $\begin{array}{l}\text { Ammeter and voltmeter testing and } \\
\text { calibration }\end{array}$ & Design \\
\hline 5 & $\begin{array}{l}\text { Electrical parameter measurement and error } \\
\text { analysis }\end{array}$ & Design \\
\hline 6 & $\begin{array}{l}\text { Composite electrical impedance } \\
\text { measurement }\end{array}$ & Design \\
\hline 7 & Harmonic wave detection and analysis & $\begin{array}{c}\text { Demonstration and } \\
\text { verification }\end{array}$ \\
\hline 8 & $\begin{array}{l}\text { Effects of harmonic waves on electrical } \\
\text { energy measurement }\end{array}$ & $\begin{array}{c}\text { Demonstration and } \\
\text { verification }\end{array}$ \\
\hline 9 & $\begin{array}{l}\text { Smart grid-oriented interactive electrical } \\
\text { energy measurement and management }\end{array}$ & \begin{tabular}{|c|} 
Demonstration and \\
verification
\end{tabular} \\
\hline 10 & $\begin{array}{l}\text { Remote control of electronic devices based } \\
\text { on the Web platform }\end{array}$ & Design \\
\hline 11 & $\begin{array}{l}\text { Principle and structure of smart } \\
\text { grid-oriented modern electrical measuring } \\
\text { instruments }\end{array}$ & $\begin{array}{c}\text { Demonstration and } \\
\text { verification }\end{array}$ \\
\hline 12 & $\begin{array}{l}\text { Application of the Internet of Things } \\
\text { technology based on a smart grid }\end{array}$ & Comprehensive \\
\hline 13 & EEM testing and calibration & Comprehensive \\
\hline 14 & $\begin{array}{l}\text { Manual and fully automatic EEM } \\
\text { calibration }\end{array}$ & Comprehensive \\
\hline 15 & $\begin{array}{l}\text { Effects of electromagnetic interference on } \\
\text { electrical measuring instruments }\end{array}$ & Comprehensive \\
\hline
\end{tabular}

\section{B. Examples of Practicum Projects}

Fig. 1 shows the design approach for an EMI industry-oriented practicum project based on the EEM module testing process, which consists of the following steps barcode scanning, module positioning, hole check, voltage check, powering on the tools, liquid crystal display (LCD) test and circuit board voltage test. After board cards are preliminarily installed, barcodes need to be scanned. The unique barcodes of the currently tested EEM circuit boards are input into the test system. Then, the circuit boards are placed in the grooves of the tools and fixed. After positioning the EEM circuit boards, the connecting wires of the test needle plate and the test voltage settings for the tools need to be checked to ensure correct parameter settings for the test equipment and correct test conditions. The EEM circuit boards that have passed the test will be passed to the next normal step: they will be subsequently employed in the entire machine assembly process. The EEM circuit boards that have failed the test will be sent to the repair system, and the erroneous or faulty units will be clearly marked.
As shown in Fig. 1, four functional units are arranged for the EMI industry-oriented instrument production and testing practicum project designed based on the EEM module testing process, namely, understanding the functional units of the EEM circuit boards, inspection of the welds on the circuit boards of the electrical measuring instruments, liquid crystal display (LCD) testing technique, and LCD fault analysis and circuit board voltage testing technique and its implementation. By matching the four previously mentioned functional units with the steps of the EEM module testing process, students who are majoring in measurement and control technology and instrumentation will have a comprehensive understanding of electrical measuring instruments in terms of research, design, manufacture and operation. Utilizing a "teaching, learning, doing" teaching method, the EMI industry-oriented practicum project based on the EEM module testing process alternates between the theoretical content of courses and the content of practicums to facilitate an understanding of the production process by students and improve their practical operational ability.

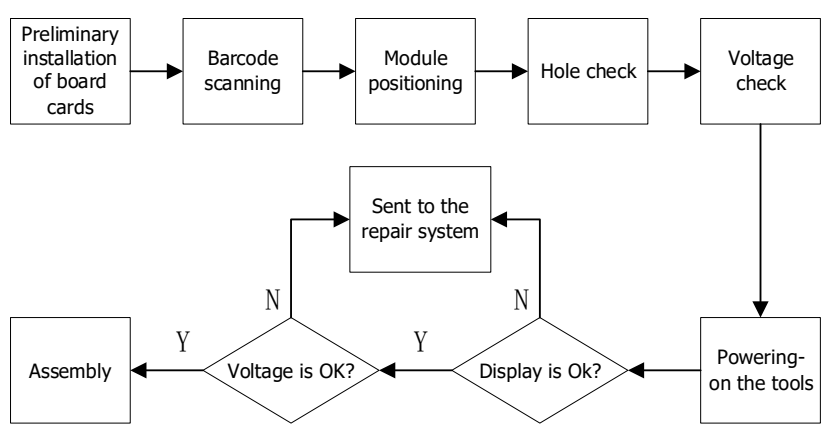

Fig. 1. EMI industry-oriented practicum project designed based on the EEM module testing process.

\section{Practicum Project Implementation and Management}

Hunan University's EIE practicum management system consists of five components, namely, a practicum management system, a practicum content system, a practicum teaching materials system, a practicum teacher supervision system and a student practicum quality system. The entire practicum management system is operated in a coordinated manner to ensure success at each step of the practicum.

The practicum management system primarily includes a series of standardized management systems that are formed for the personnel, matter, units and processes involved in the teaching given to EIE students of Hunan University during their practicum in enterprises in the EMI industry. A comprehensive practicum management system (suitable for specific situations) can provide strong support that will ensure effective progression of practicum teaching.

The practicum content system primarily includes the specific tasks of the practicum process. This system should be appropriately adjusted based on the specific situations of EIE students of Hunan University and the requirements for disciplinary and market development.

The practicum teaching materials system includes the paper and electronic teaching materials that are employed in the practicum process. Practicum teaching materials relatively significantly differ from the course materials used at school because they focus on ensuring that the EIE 
students of Hunan University learn to formulate standards for technological operation and organize and manage production. The practicum teacher supervision system includes the basic methods and regulations that are designed for teachers during the practicum process.

The student practicum quality system primarily includes the quality control standards for each step of the practicum for EIE students of Hunan University. This system is an important means to ensure that the practicum attains the desired goal and provides a basis for further adjustment and optimization of the practicum work system.

\section{CONCLUSION}

Establishing practicum projects that reflect the latest industrial and technological developments is an important component of $3 \mathrm{E}$ construction. The EMI industry in China has substantial demand for EIE professionals but is experiencing a severe shortage of highly qualified EIE engineers. Therefore, designing practicum projects that are oriented to the EMI industry and improve the results of the practicum teaching of EIE students are important parts of the investigation of $3 \mathrm{E}$ training models.

Based on the experience gained with the reform of practicum projects for the EIE students of Hunan University, the demand of the EMI industry for EIE professionals in a $3 \mathrm{E}$ construction background is analyzed in this paper, and practicum projects that feature engineering practicums are abstracted and designed from university-industry cooperative projects, modern industrial scientific research and the forefront of production, which provide an important reference for $3 \mathrm{E}$ reform of EIE professionals.

Through this research, the Hunan University combines production, scientific research, and management of the base with students' production internships and graduation designs, and gradually forms a training model for the in-depth fusion of school and enterprise monitoring and control technology and instrumental innovation talents, and realizes the base company, school, and Student's win-win.

\section{REFERENCES}

[1] P. Y. Chen, "Transnational education: Trend, modes of practices and development," International Journal of Information and Education Technology, vol. 5, no. 8, p. 634, 2015.

[2] J. M. Kelly, "Engineering education in the 21st century: creativity, collaboration, invention," International Journal of Information and Education Technology, vol. 3, no. 2, p. 240, 2013.

[3] A. Rugarcia et al., "The future of engineering education I. A vision for a new century," Chemical Engineering Education, vol. 34, no. 1, 16-25, 2000.

[4] M. Borrego et al., "Diffusion of engineering education innovations: A survey of awareness and adoption rates in US engineering departments," Journal of Engineering Education, vol. 99, no. 3, pp. 185-207, 2010.

[5] A. Yadav et al., "Problem-based learning: Influence on students' learning in an electrical engineering course," Journal of Engineering Education, vol. 100, no. 2, pp. 253-280, 2011.

[6] J. C. Perrenet et al., "The suitability of problem-based learning for engineering education: theory and practice," Teaching in Higher Education, vol. 5, no. 3, pp. 345-358, 2000.

[7] T. Beuth et al., "The road to" ITIV Labs"-An integrated concept for project-oriented systems engineering education," International Journal of Information and Education Technology, 2015, vol. 5, no. 4, p. 250.
[8] M. Joshi and R. Chugh, "New paradigms in the teaching and learning of accounting: Use of educational blogs for reflective thinking," International Journal of Education and Development Using Information and Communication Technology, vol. 5, no. 3, p. C1, 2009.

[9] C. L. Chiang and H. Lee, "The effect of project-based learning on learning motivation and problem-solving ability of vocational high school students," International Journal of Information and Education Technology, 2016, vol. 6, no. 9, 709-712.

[10] S. Rosaline and J. R. Wesley, "Factors affecting students' adoption of ICT tools in higher education institutions: An Indian context," International Journal of Information and Communication Technology Education (IJICTE), 2017, vol. 13, no. 2, pp. 82-94.

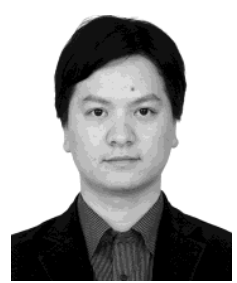

He Wen was born in Hunan, China, in 1982. He received the B.Sc., M.Sc, and Ph.D. degrees in electrical engineering from Hunan University, Hunan, China, in 2004, 2007, and 2009, respectively. He is currently an associate professor with the College of Electrical and Information Engineering, Hunan University, China. His present research interests include electrical contact reliability, wireless communications, power system harmonic measurement and analysis, power quality, and digital signal processing. Also, he is the deputy director of Hunan Province Key Laboratory of Intelligent Electrical Measurement and Application Technology.

He Wen is an associate editor of the IEEE Transactions on Instrumentation and Measurement, and a member of editorial board of Fluctuation and Noise Letters.

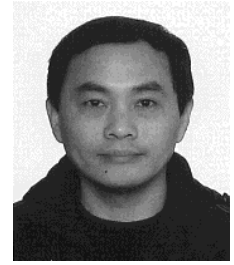

Zhaosheng Teng was born in Hunan, China, in 1963. He received the B.Sc., M.Sc., and Ph.D. degrees in electrical engineering, all from Hunan University, Hunan, China, in 1984, 1995, and 1998, respectively. From 1999 to 2000, he was a postdoctoral research fellow with the National University of Defense Technology. Since 2000, he has been a Professor at Hunan University. His main interest and research field are power quality monitoring, harmonic analysis, information fusion, and electrical measurement.

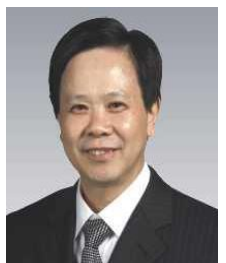

Jing Zhang was born in Hunan, China, in 1957. He received the B.Sc., M.Sc., and Ph.D. degrees in automation engineering, all from Hunan University, Hunan, China, in 1982, 1994, and 1997, respectively. From 1984 to 1993 , he was a associate professor with Hunan University. Since 1994, he has been a Professor at Hunan University. His main interest and research field are control engineering, computer engineering, and artificial intelligence.

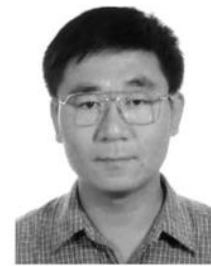

Feng Wang was born in Liaoning, China, in 1972. He received the B.Sc., M.Sc., and Ph.D. degrees in electrical engineering, from Xi'an Jiaotong University, Shenyang University of Technology, and Xi'an Jiaotong University, China, in 1994, 1999, and 2003 , respectively. From 2003 to 2004, he was a postdoctoral research fellow with the Technische Universität Darmstadt, Germany. Since 2005, he has been a professor at Hunan University. His main interest and research field are high voltage engineering, and electrical insulation technology.

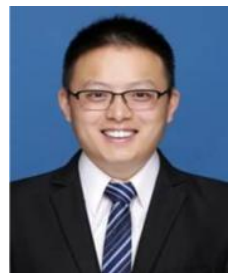

Zhikang Shuai was born in Shandong, China, in 1982 $\mathrm{He}$ received the B.S. and Ph.D. degree from the College of Electrical and Information Engineering, Hunan University, Changsha, China, in 2005 and 2011, respectively, all in electrical engineering. He was with the Hunan University, as an assistant professor between 2009 and 2012, and an associate professor in 2013. Starting in 2014, he became a professor at Hunan University. His research interests include power quality control, power electronics, and Microgrid stability analysis and control.

$\mathrm{He}$ is a recipient of the 2010 National Scientific and Technological Awards of China, the 2012 Hunan Technological Invention Awards of China, the 2007 Scientific and Technological Awards from the National Mechanical Industry Association of China. 